\title{
The Developments of piezoelectric Materials and Shape Memory Alloys in Robotic Actuator
}

\author{
Safar Saeed Mohammed ${ }^{1,2 *}$, Mediha Kök ${ }^{1}$, Ibrahim Nazem Qader ${ }^{1,2}$, Fethi Dağdelen ${ }^{1}$ \\ ${ }^{1}$ Firat University, Faculty of Science, Department of Physics, Elazig, Turkey (ORCID:0000-0003-4804-2632; 0000-0003-1167-3799) \\ ${ }^{2}$ University of Raparin, College of Science, Department of Physics, Sulaymaneyah, Iraq (ORCID:0000-0003-4804-2632; 0000-0001-7404-4311)
}

(First received 1 December 2019 and in final form 22 December 2019)

(DOI: 10.31590/ejosat.653751)

ATIF/REFERENCE: Mohammed, S. S., Kök, M., Qader, I. N. \& Dağdelen, F. (2019). The Developments of piezoelectric Materials and Shape Memory Alloys in Robotic Actuator. European Journal of Science and Technology, (17), 1014-1030.

\begin{abstract}
There is a high demand for functional smart materials, especially for new material groups in advanced Technologies. These materials are used in the actuator, sensor, control systems, and robotic systems, in addition, they can be hybridized with traditional material to create a particular function. Piezoelectric materials and shape memory alloys are the most important families among these groups. This review includes an overview of shape memory alloys (SMAs) and piezoelectric material actuator systems in terms of robotic applications. The theoretical background of each SMAs and piezoelectric materials is well explained. Different types of each system are interpreted. Using actuator-based SMAs and piezoelectricity in the robotic area is extensively overviewed. Some weaknesses and challenges facing such systems have discussed through recent studies in the literature.
\end{abstract}

Keywords: Piezoelectric Materials; Shape Memory Alloys; Actuators; Robotic Actuator Systems

\section{Robotik Aktüatörde Piezoelektrik Malzemelerin ve Şekil Hatırlamalı Alaşımların Gelişimi}

$\ddot{O} z$

Teknolojik Gelişmeler içinde, yeni bir malzeme grubu olan, fonksiyonel akıllı malzemelere yüksek oranda bir talep vardır. Bu malzemeler geleneksel malzemelerin işlevleri dışında, aktüatör (harekete geçirici), sensör, kontrol sistemleri ve robotik sistemlerinde kullanılırlar ve Bunlardan en önemli iki tanesi; piezoelektrik malzemeler ve şekil hatırlamalı alaşımlardır. Bu derlemede, şekil hatırlamalı alaşımlar (ŞHA) ve piezoelektrik malzemelerin aktüatör sistemlerini inceleyen genel bir bakış içerir. ŞHA lar ve piezoelektrik malzemelerin herbirinin teorik özellikleri detaylı bir şekilde izah edildi. Her iki sistemin farklı çeşitleri değerlendirildi. Robotik alandaki aktüatör tabanlı ŞHA ve pizeoelektrikler geniş bir şekilde incelendi. Bu sistemlerin karşı karşıya kaldığı bazı zayıflıklar ve zorluklar literatürdeki son çalışmalar ile tartışılmıştır.

Anahtar Kelimeler: Piezoelektrik malzemeler; Şekil hatırlamalı Alaşımlar; Aktüatörler; Robotik aktüatör sistemler

\footnotetext{
${ }^{*}$ Corresponding Author: University of Raparin, College of Science, Department of Physics, Sulaymaneyah, Iraq and Firat University, Faculty of Science, Department of Physics, Elazig, Turkey ORCID:0000-0003-4804-2632, safar.saeed@ raparinuni.org
} 


\section{Introduction}

Nowadays, technology has a major and powerful role in human life, and it is very important to develop civilization (Arber, 2009; Carneiro, 1974), society (Drucker, 2012), and education (Chance, Ben-Zvi, Garfield, \& Medina, 2007). Also, it has an answer to most of our daily problems. The technology is multidisciplinary with a combination of imagination, material science, and engineers who could arrange all together to solve the existing problems. It can be seen that technology with all complexity could change lifestyle and gives another form to citizens and countryside people. In the previous centuries that technology had no absolute authority, life was simple however it was very tough without technology. However today technology controlled every scope of daily life, and there are many activities that cannot be performing without technology, so there is no escape from them (Prensky, 2008).

One of the advanced fields of technology is robotic. Robotics in this modern age has a big influence on various fields such as surgery, service, automotive, food, engineering, and education (Advincula \& Song, 2007; Brose et al., 2010; Chua, Ilschner, \& Caldwell, 2003; Jacobsen, Berger, \& Horgan, 2003; Karabegović, 2016; Kawamura, Bagchi, Iskarous, \& Bishay, 1995; Mubin, Stevens, Shahid, Al Mahmud, \& Dong, 2013; Qader, Kök, Dağdelen, \& Aydogdu, 2019; Robins, Dautenhahn, Te Boekhorst, \& Billard, 2005; Roth, 2002). Inventors and designers in the robotic field are continuously trying to improve robotic systems, by designing new types of robots and improving the quality of them using high-quality primary materials. Since shape memory alloys and piezoelectric materials have interesting behaviors, so they role as sensors and actuators in robotic systems (Culp, 1992; B. Kim, Lee, Lee, Kim, \& Lee, 2006; Y. Tanaka \& Yamada, 1991).

SMAs are easily recovered to their original shape after deformation, this feature is so called shape memory effect (Buytoz, Dagdelen, Qader, Kok, \& Tanyildizi, 2019; Dagdelen, Aldalawi, Kok, \& Qader, 2019; Dagdelen, Kok, \& Qader, 2019; Kök et al., 2020; Kök, Zardawi, Qader, \& Kanca, 2019; Qader, Kök, \& Dağdelen, 2019), because of this property SMA-based actuators are applied in a locomotion robot, manipulator and microrobot (Y. Tanaka \& Yamada, 1991). Also, piezoelectric materials capable to convert mechanical energy into electrical energy and conversely by applying an external force they can make a voltage. These abilities are known as the piezoelectric effect (Jaffe, 2012; Kolesar, 1998). Therefore piezoelectric materials can also be handled as an actuator in robotic systems (Culp, 1992; Dadfarnia, Jalili, Xian, \& Dawson, 2003; Hunter, Hollerbach, \& Ballantyne, 1991; Tzou, Lee, \& Arnold, 2004).

In this review, it is aimed to focus on some background about robotic actuator systems, and it has demonstrated some brief information about SMAs, and piezoelectric materials, and their applications in the robotic systems as an actuator.

\section{Theoretical Background}

Recently, smart materials controlled a wide range of modern technology. Smart materials are used by engineers and designers to improve the traditional inventions. Smart materials are novel materials that can solve some complexity, spatially in actuating systems (Addington \& Schodek, 2012). Among all types of smart materials, piezoelectric and SMAs having more applications comparing to the other families, because they have piezoelectric effect and shape memory effect, respectively.

\subsection{Piezoelectric Materials}

A piezoelectric material is a type of smart material that able to convert electrical potential energy (voltage) into mechanical energy. Conversely, when it is squeezed or elongated by an external force, electrical potential energy can be obtained, which its polarity depends on the type of deformation (Figure 1) (Starr \& Wang, 2015; Tichý, Erhart, Kittinger, \& Privratska, 2010). Thus the piezoelectricity is a reversible process. The converse piezoelectric effect, where the piezoelectric material deforms by applying a voltage, is used for accurate actuation and running in some control applications, while the direct effect is used for sensor applications (Kolesar, 1998; Tzou et al., 2004; Tzou \& Natori, 2001).

Table 1. Common piezoelectric materials (Tzou et al., 2004).

\section{Natural Piezoelectric materials}

$>$ Single crystal (Quartz crystals, Rochelle salt, Lithium niobate, etc.)

$>$ Nano crystalline (Rubber glass, parafine, etc.)

$>$ Biological (Dry bone, enamel, etc.)

$>$ Nonbiological (Rochelle salt, silicon oxide (Sio2), etc.)

\section{Synthetic Piezoelectric materials}

$>$ Crystalline (Gallium phosphate (GaPo4), Lithium sulfate (SI2SO4), etc.

$>$ Ceramic (lead lithium zirconate titanate (PLZT), Zinc oxide (ZNO), etc.

$>$ Polymer (Polyvinylidene fluoride(PVF2), lead zirconate titanate (PZT), etc. 

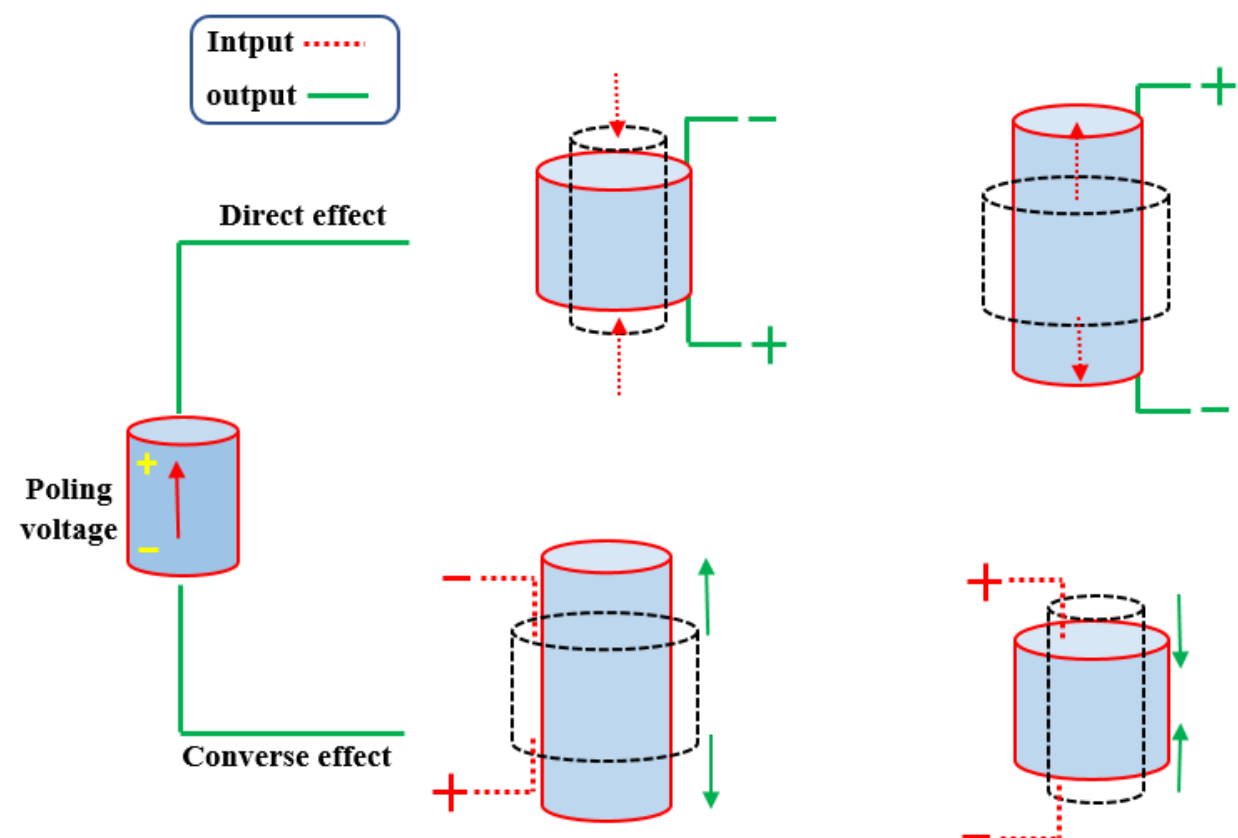

Figure 1. Direct and inverse Piezoelectric effects (Jbaily \& Yeung, 2015).

Historically, in the 1880 piezoelectricity phenomenon was observed, by Curie brothers (Jacques and Pierre). They detected a sign of electricity when they applied a mechanical pressure to a quartz crystal. Also, a strain was observed when they applied an electrical field to that quartz. Piezoelectricity is an electromechanical process that has coupling elastic (i.e. dynamic coupling) field and the electric (i.e. static coupling) field (Figure 2) (Tichý et al., 2010; Tzou et al., 2004).

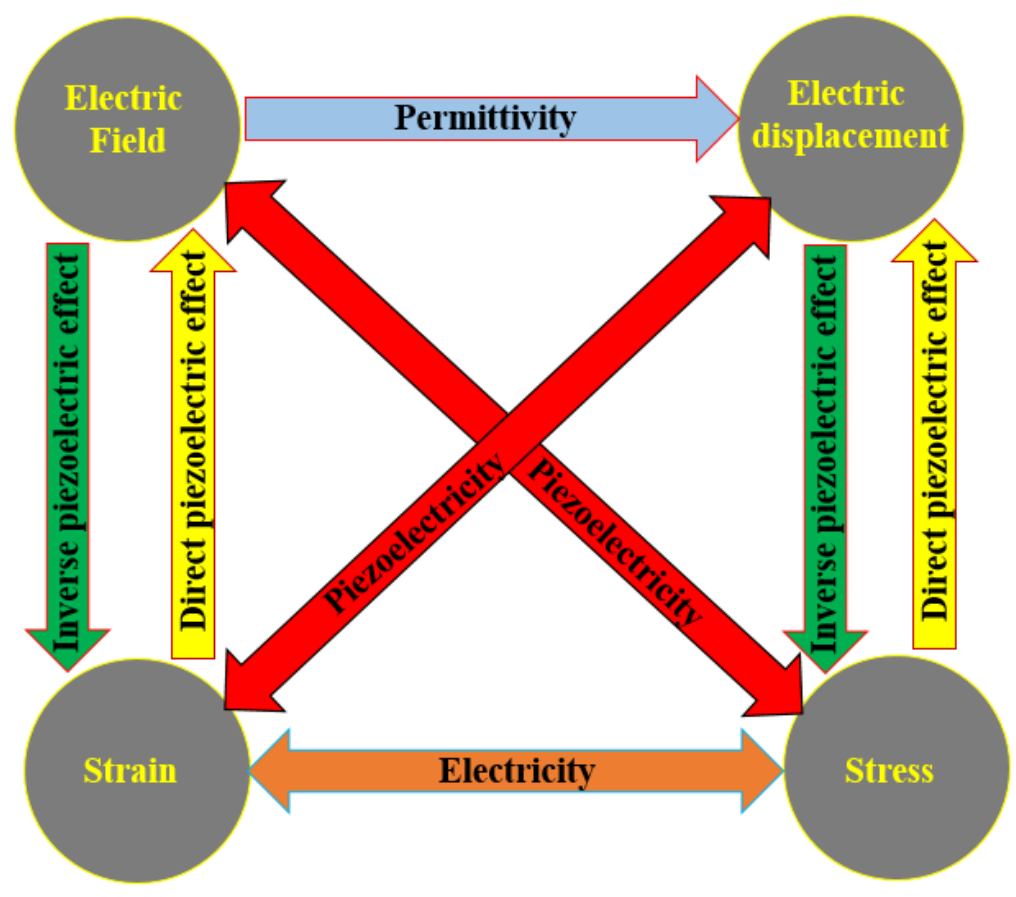

Figure 2. Piezoelectricity (electromechanical coupling) (Tzou et al., 2004).

Many common natural and synthetic piezoelectric materials are listed in Table 1. The synthetic materials are non-piezoelectric, but when a high electric field at an elevated temperature is applied to them they get piezoelectric property. (Dökmeci, 1983).

\subsection{Shape Memory Alloys}

A shape memory alloys (SMA) is a class of advanced materials (Alaneme \& Okotete, 2016; Jani, Leary, Subic, \& Gibson, 2014). They have two main phases which are austenite and martensitic. Austenite is a high-temperature phase, where the SMAs are more 
rigid, whereas in the martensite is known as the low-temperature phase. SMAs can be easily strain recovered (Figure 3) (Ma, Song, \& Lee, 2004; Toru, 2008). A SMA can transform from martensite to austenite phase, when its temperature is increased and (Aydoğdu et al., 2016; Dağdelen, Malkoç, Kök, \& Ercan, 2016; Kök \& Ateş, 2017; Qader, Kök, \& Dağdelen, 2019). Also, SMAs have the ability to memorize their previous shape when their temperature elevated to the high-temperature phase, this behavior is known as shape memory effect (SME) (Alaneme \& Okotete, 2016; Bogue, 2009; Ochoński, 2010; Qader, Kök, \& Dağdelen, 2019; Rao, Srinivasa, \& Reddy, 2015). There is three known SME that have been explained in the next subsections (Toru, 2008).

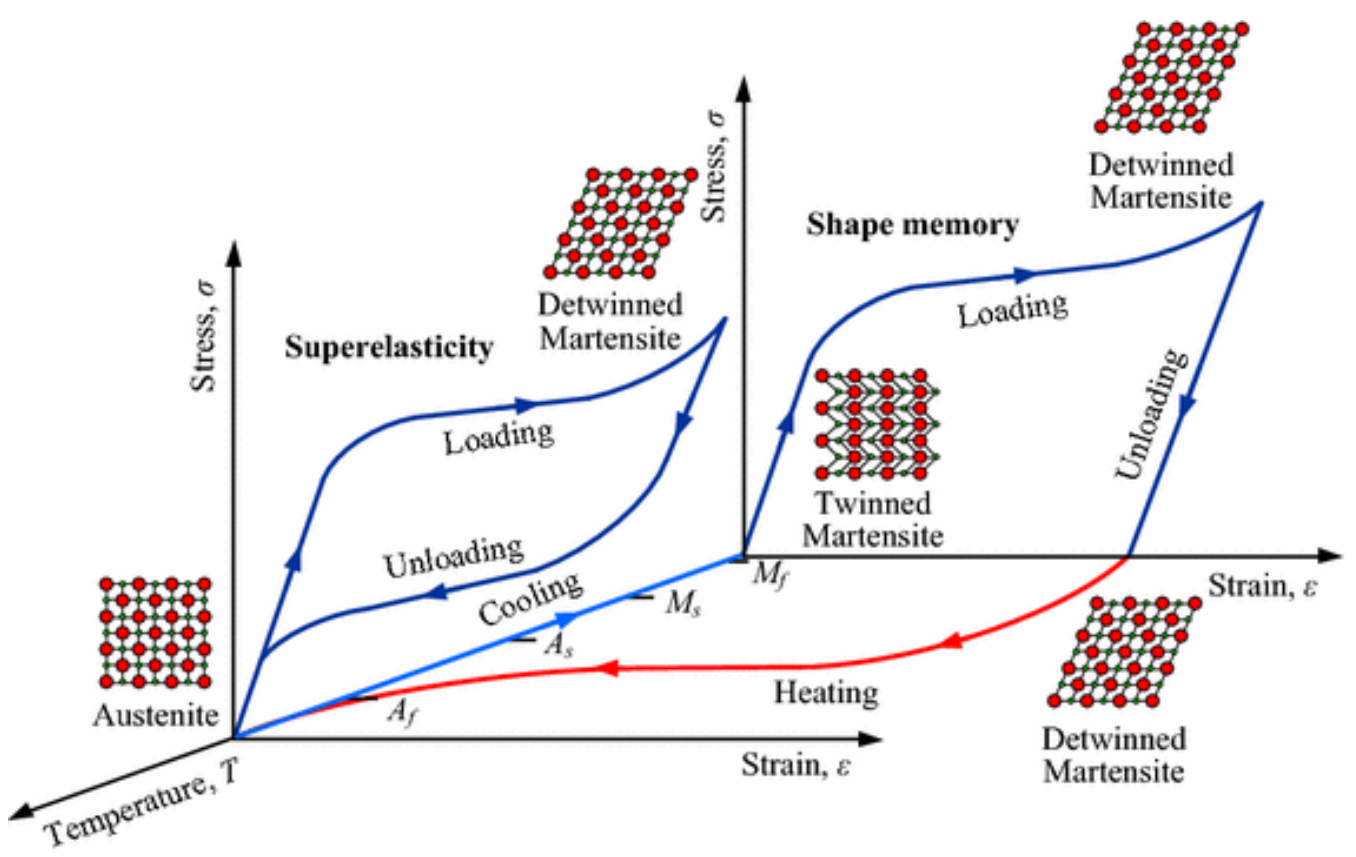

Figure 3. Schematic diagram of different phases of a SMA. Superelasticity (SE) and shape memory effect (SME) are the two important characteristics of a SMA(B. Wang \& Zhu, 2018).

\subsubsection{One-Way SME}

Normally, similar to other conventional materials, a SMA undergoes a plastic deforming, it can return to its previous state when it heated up to above critical temperature (eutectoid temperature) (Sofla, Elzey, \& Wadley, 2008). Therefore one way SME is one of the fundamental key points in SMA-based actuators (Toru, 2008).

\subsubsection{Two-Way SME}

Unlike one-way SME, a two-way-SMA can show SME in either higher temperature or lower temperature phase. Thus, it can be given two different original forms through a training process (W. Huang \& Toh, 2000).

\subsubsection{Pseudoelasticity}

Pseudoelasticity (or superelasticity) is another superior of SMAs that let them to directly recover their original shape and size in an isothermal process. The applying force just transforms crystal structure of the alloy from austenite to martensite phase and after removing the load the alloy can strain to recover with consuming some energy into heat, which produced through the friction of moving atoms during phase transformation process (Otsuka \& Shimizu, 1986). 


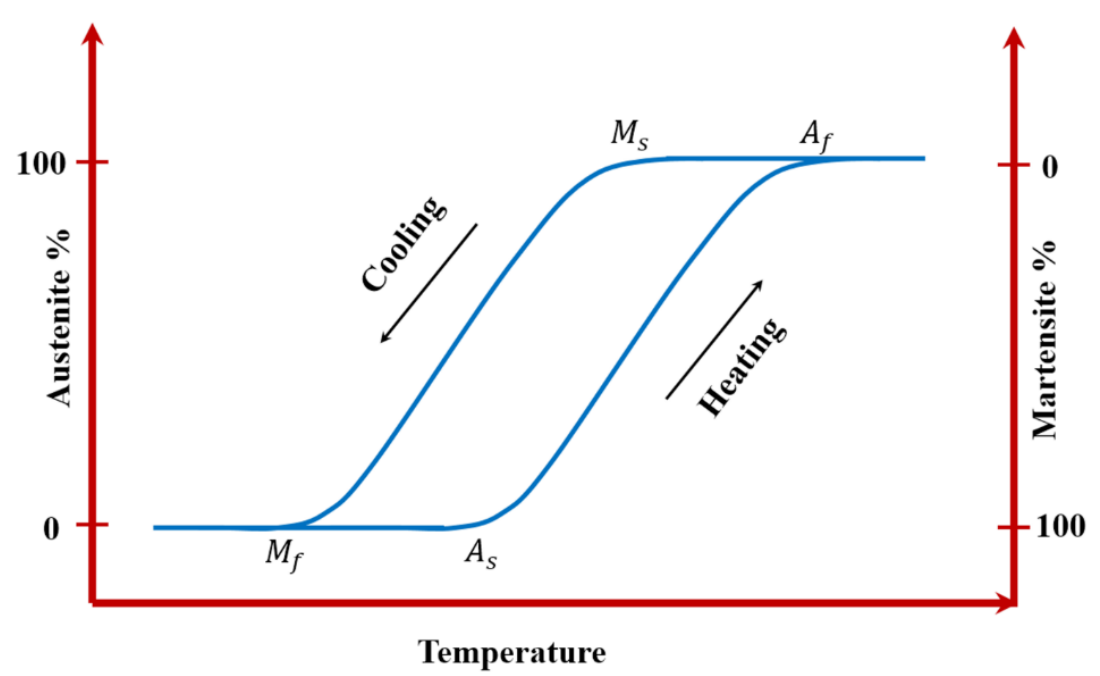

Figure 4. Transformation temperatures curve (Toru, 2008).

The transformation temperature of SMAs is one of the most important factors in all SMA-based technologies. Figure 4 shows transformation parameters, including austenite start $\left(A_{s}\right)$, austenite finish $\left(A_{f}\right)$, martensite start $\left(M_{s}\right)$, and martensite finish $\left(M_{f}\right)$. Also, temperature hysteresis is a range of temperature between austenite and martensite phase transitions (Ercan, Dagdelen, \& Qader, 2019; Kok, Al-Jaf, Çirak, Qader, \& Özen, 2019; Kök et al., 2020; Toru, 2008). The SMAs are classified into SIMA (class I) and (class II), which has $A_{s}>M_{s}$ and $A_{s}<M_{s}$, respectively.

\subsection{Actuators}

Actuators are mechanical devices that are utilizing to perform various types of movements. They have different functionalities, which depends on technological systems. Some application areas with some related examples have been listed in Table 2 (Huber, Fleck, \& Ashby, 1997; Mavroidis, 2002). Generally, all converts an additional type of energy (e.g. electricity, flowed air, and liquid) into a mechanical motion (Cattafesta III \& Sheplak, 2011; Huber et al., 1997; Janocha, 2004; Tan, 2002).

\subsubsection{Types of Actuators}

Depends on the principle of working, and its primary materials, actuators can be classified into several types (Cura, Cunha, Aguiar, \& Cliquet Jr, 2003; Huber et al., 1997; Pons, 2005).
a. Piezoelectric actuators
b. Shape memory alloy actuators
c. Magnetostrictive actuators
d. Thermal expansion actuators
e. Hydraulic and pneumatic actuators
f. Electromagnetic actuators
g. Natural actuators
h. Actuators based on material state changes

All of these types of actuators have special properties, so it makes them be used in various areas and different technological fields. Among the aforementioned types of actuators, both piezoelectricity and SMA-based actuators have been focused on in this study. Also, their applications are specified for robotic systems. 
Table 2. Some application areas of actuators (Huber et al., 1997).

\begin{tabular}{|c|c|}
\hline Field & Examples \\
\hline Aerospace & $\begin{array}{l}\text { Flight control surfaces (Addington \& Schodek, 2012) } \\
\text { Landing gear movement (Howard \& Walker, 1993) } \\
\text { Nose wheel steering (Bennett, Mecrow, Atkinson, Maxwell, \& Benarous, } \\
2011 \text { ) } \\
\text { Air brakes (Uttley, Chambers, Blackwell, \& Weller, 2002) } \\
\text { Powered doors/hatches (S. G. Kim, Franklin, \& Conner, 1995) }\end{array}$ \\
\hline Automotive & $\begin{array}{l}\text { Braking (Solmaz, Akar, \& Shorten, 2008) } \\
\text { Tappets (Duchaud, Hlioui, Louf, Ojeda, \& Gabsi, 2014) } \\
\text { Active suspension (Poussot-Vassal et al., 2008) } \\
\text { Active engine mounts (Swanson, 1993) } \\
\text { Airbag deployment (Yasui \& Naito, 1981) }\end{array}$ \\
\hline Industrial equipment & $\begin{array}{l}\text { Automation equipment (Book, 1986) } \\
\text { Numerically controlled (Kumbhar \& Gawade) } \\
\text { Machines (Nakao, Tokunaga, Yamane, \& Saka, 1999; Schoeny \& Nelson, } \\
\text { 2007; Yoichi, 2006) } \\
\text { Presses (Shimao, Inoue, \& Kurata, 2013) } \\
\text { Lifting equipment (Yongning \& Fengbai, 1988) }\end{array}$ \\
\hline Electrical goods & $\begin{array}{l}\text { Automatic switches/thermostats (Huber et al., 1997) } \\
\text { Video/compact disc reading head (Huber et al., 1997) } \\
\text { Camera auto-focus (Goldenberg, Shabtay, Mendlovic, \& Kali, 2014) }\end{array}$ \\
\hline Developing technology & $\begin{array}{l}\text { Active control of structures (Balamurugan \& Narayanan, 2008) } \\
\text { Vibration suppression (Denoyer \& Kwak, 1996) } \\
\text { Active materials (J.-S. Park \& Kim, 2005) } \\
\text { Surgical equipment (Culjat et al., 2008) } \\
\text { Robotics (Daerden \& Lefeber, 2002; Daerden, Lefeber, Verrelst, \& Van } \\
\text { Ham, 2001; De Rossi, Suzuki, Osada, \& Morasso, 1992; Hines, Petersen, } \\
\text { Lum, \& Sitti, 2017; Kheirikhah, Rabiee, \& Edalat, 2010) } \\
\text { Space structure deployment (Y. S. Park et al., 2005) }\end{array}$ \\
\hline Instrumentation & Atomic force microscope (Sulchek et al., 1999) \\
\hline
\end{tabular}

\subsubsection{Piezoelectric Actuators}

This type of actuator has widely used in modern technology because it has a fast response to applied signals and has high stiffness (Addington \& Schodek, 2012; Dosch, Inman, \& Garcia, 1992; Lee, 1990; Smith et al., 2012; Uchino, 2017). Piezoelectric actuators are based on their elementary materials that are piezoelectric materials. Piezoelectric materials have an interesting behavior that is called the piezoelectric effect. This effect has two states, which are direct and converse piezoelectric effects. Basically, a piezoelectric actuator shows a piezoelectric effect, where the material able to convert electrical energy into a deformation, which consequently can be utilized as a mechanical motion (Figure 1a) (Chuanzhong, 1993). The magnitude of the piezoelectric effect is based on the applied electrical field.

These actuators have a small size and low mass density. Moreover, since they have a high range of power density and they have a high torque (Cura et al., 2003), therefore they have plenty of technological applications in automotive, aerospace, and biological and medical purposes. They are one of the best-known actuators for robotic systems because they have high bandwidth, high power density and ability to operate on direct current (DC) without need for lubrication or cooling. Also, they can be handled in a miniatured device because they are simple and have a comparably small size (Oldham, Rhee, Ryou, Polcawich, \& Pulskamp, 2009; Wood, Steltz, \& Fearing, 2005). If a thin-film piezoelectric actuator integrated with microstructure of silicon and polymer, it can produce a torque of motion in robotic legs (Oldham et al., 2009).

\subsubsection{SMA-based Actuators}

SMA-based actuators are one of the interesting types of actuators that have more applications in modern technology (Chaudhry \& Rogers, 1991; Colorado, Barrientos, Rossi, \& Breuer, 2012; Kök et al., 2020; Seelecke \& Muller, 2004; Webb, Lagoudas, \& Kurdila, 1998) because they possess an ability known as shape memory effect (SME). Therefore a deformed SMA able to return to its original 
form by aid of a convenient stimulus (Alaneme \& Okotete, 2016; Bogue, 2009; Ochoński, 2010; Qader, Kök, \& Dağdelen, 2019; Rao et al., 2015).

Although SMA-based actuators have small and compact size, they are used for advanced systems because they can produce a large actuating force (200 MPa), which 570 times as larger as human muscle force (Hunter \& Lafontaine, 1992), and 25 times as greater as the force produced by electro-active polymer (EAP) (Mavroidis, 2002; Pelrine \& Kornbluh, 2003). Furthermore, SMA-based actuators have three basic types, including one-way, biased, and two-way SMA actuators (Figure 5). Figure 5a shows a wire that can only recover its predetermined shape (e.g. coiled form) when heated up to the austenite phase, it is an example of a one-way SMA actuator. Although the first type that heat energy is the stimulus force for strain recovery, Figure $5 \mathrm{~b}$ demonstrates a in biased SMAbased actuators that biased by another spring which returns the SMA to its original shape through the restoring force. The spring, before installation, is deformed in the high-temperature phase (austenite), and thus, the energy is stored in the spring as potential energy. This stored energy can release when the SMA cooled until it transforms from austenite to transform the martensite phase. The bias spring can be used to return the deformed SMA to its original shape, which makes a movement. The biased type of SMA is a hybrid system and based on the heating/cooling process (Figure 5b). Lastly, the two-way SMA-based actuator is similar to biased SMA actuators, can continuously produce movement with the opposite direction but two opposing SMA wires are used instead of biased spring (Liang \& Rogers, 1992).

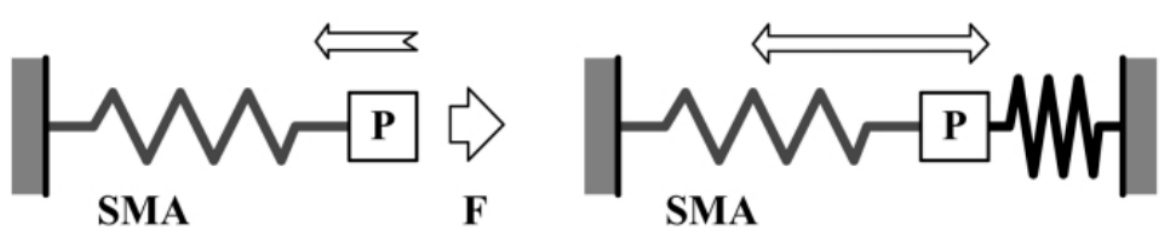

(a)

(b)

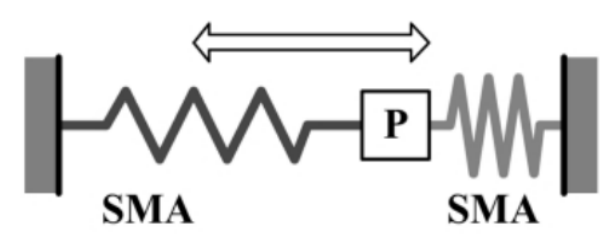

Figure 5. (a) One-way, (b) Biased, and (c) two-way SMA-based actuator (W. Huang, 2002).

\section{Applications}

\subsection{Fingered Robot Hand}

There is a plenty prototype that proposed robot hand with different mechanisms. In these prosthesis different type of actuators have been used with various materials properties (Ahmadi et al., 2015; Price, Jnifene, \& Naguib, 2007; Villoslada, Flores-Caballero, Copaci, Blanco, \& Moreno, 2014). Takashi Maeno et al. (Maeno \& Hino, 2006) proposed a five-figure robot hand with four degrees of freedom (DOF) per figure, which was similar to a real human hand. SME was utilized to move each movable part in its pre-given function. Figure 6a shows the entire prototype of the miniature robot hand in its normal mode. The robot is monitored to pick up a sphere with all fingers (Figure 6b). Each part of a finger is labeled in Figure 6c. Each band can be controlled with a wires SMA through flipflopping between austenite and martensite phases, which gives two different modes to each band. 

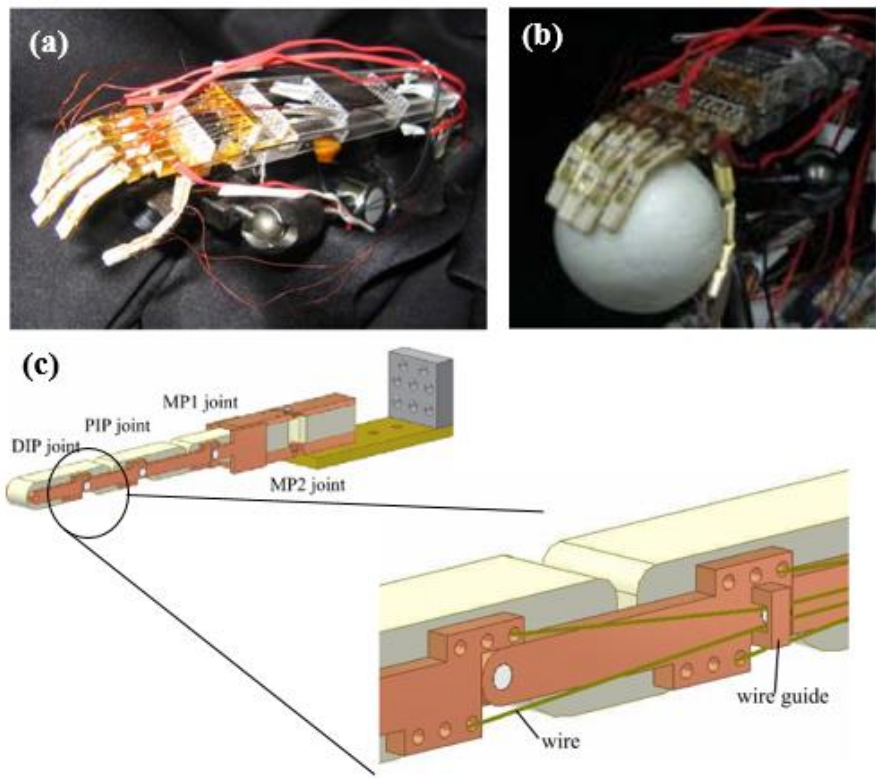

Figure 6. (a) The entire prototype of the miniature robot hand. (b) Picking up a ball by all fingers of the robotic hand. (c) Threedimensional image for one of the fingers (Maeno \& Hino, 2006).

\subsection{Robotic Arm}

The robotic arm is one of the important parts of robotic technology, which is paid attention by engineers. The robot should be programmed such that it almost has the same functionality as a human arm, i.e. the robotic arm has to bands in its fingers and all together should work in harmony. Therefore, organizing or controlling the motion and vibration of the robotic arm is very important. A. Inoue and M. Deng (Inoue \& Deng, 2007) were used as an adaptive controller to monitor the vibration of a flexible arm in a robotic system. They used a piezoelectric actuator as an adaptor (Figure 7), because this kind of actuator has a small size and low mass, therefore it was embedded along the robotic arm.

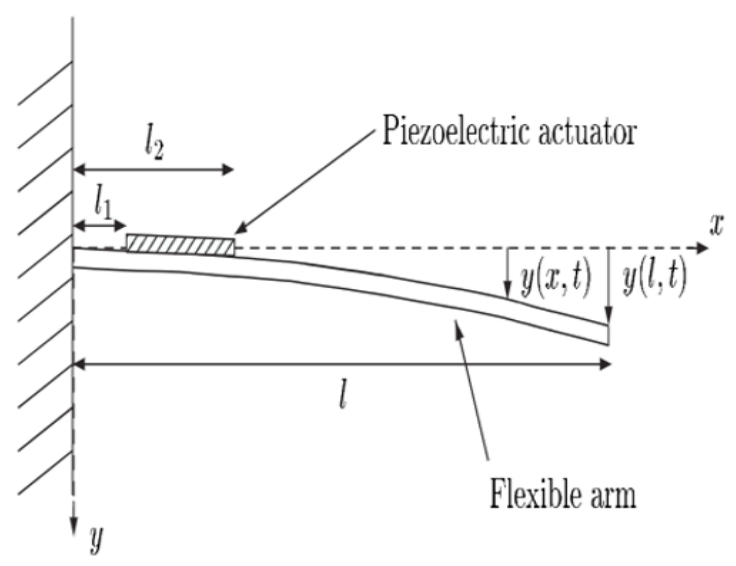

Figure 7. Flexible robotic arm with a piezoelectric actuator controlled by an adaptor (Inoue \& Deng, 2007).

\subsection{Endoscopic Robotic Surgery}

Robots have made endoscopic surgery easier and profession. In this operation, a robot sends into the related human body for looking at the corresponding organs to diagnose and performing a proper operation on the targeted organ (Quinones-Hinojosa, 2012). Also, sometimes it can be used for sucking out obstructing material (e.g. sediment dregs inside the body or sampling a small part of an organ for medical testing) with tiny forceps (Figure 8). There are some actuators embedded in the robot, which are made as spring with shape memory property. These actuators give a snake-like motion to the protheses and can control its motion. Ikuta et al. (Ikuta, Tsukamoto, \& Hirose, 1988) used an actuating system based on SMA with electric resistance feedback to improve the active 
endoscope. Also, L Liu, et al. (Liu, Towfighian, \& Hila, 2015) used a hybrid consist of SMA actuator (based on SME) and piezoelectric actuator (based on converse piezoelectric effect) to move a capsule endoscopy (wireless endoscopy).
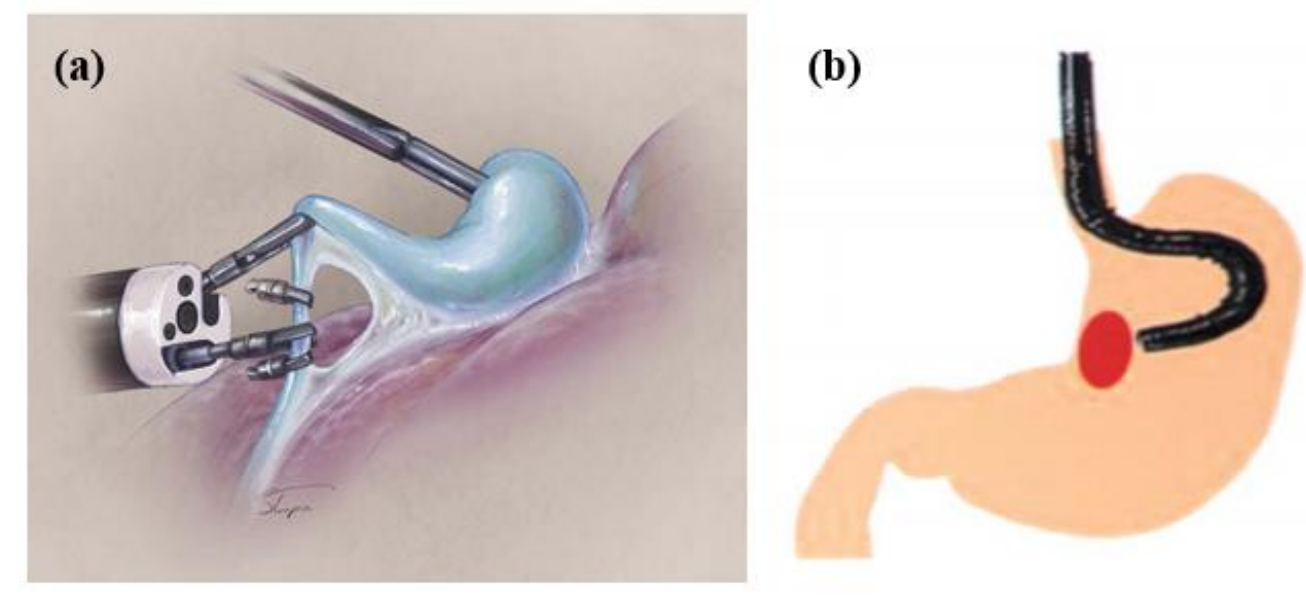

Figure 8. The endoscopy for (a) sampling a small tissue of an organs for medical test, and (b) a sucking out obstructing material (Astudillo, Sporn, Bachman, Miedema, \& Thaler, 2009; Ramos, Zundel, Neto, \& Maalouf, 2008).

\subsection{Soft Robots}

Soft robots have widely used in high-tech because they can be grabbing on soft objects. They can be used to a small extent, to have a continues motion, and they do not cause injury while they interacted with the human body (Shi et al., 2019). Similar to the other robots, these robots are also used actuators for performing their actions. Researchers are focused on SMA-based actuators in soft robots instead of DC motors because they occupy a smaller size compared to the DC motors, while their output force is the same rate (Sohn, Kim, \& Choi, 2018). Mazzolai et al. designed an octopus robot, with coils made of SMAs. The coils were responsible for actuating octopus arms, and also, they could elongate as well (Mazzolai, Margheri, Cianchetti, Dario, \& Laschi, 2012). Furthermore, Z. Shi et al. manufactured an inchworm crawling robot base on SMA-wires. The SMA is able to have a flexible motion in the muscles' fiber (Figure 9) (Shi et al., 2019).

(a)

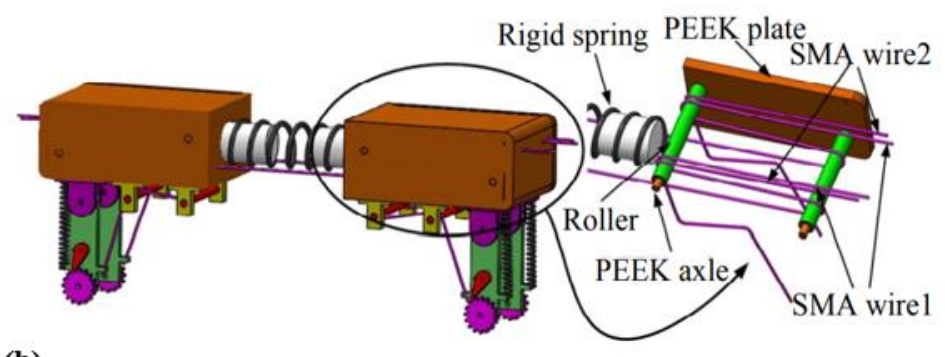

(1)

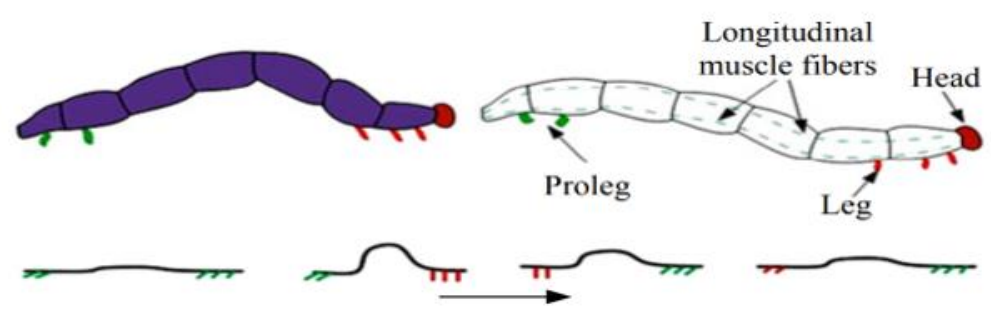

Figure 9. (a) The connection mechanism of SMA-based actuating wires in a crawling robots' legs. (b) The motion style of the inchworm crawling robot (Shi et al., 2019). 


\subsection{Robotic Leg}

The designers and researchers in the robotic area always trying to reduce the size of robots, especially in robotic legs because the movement of the robot depends on the shape and ability of its legs (Laumond, 1998). The miniaturization in robots has some advantages, because the robots can walk in some restricted locations, e.g. inside a water pipe (Gray \& Zhu, 2007), in the rubble (Casper \& Murphy, 2003), and even inside the human body (Dolghi et al., 2011). On the other hand, miniaturization process comes with some restrictions, because designing a power source, sensor, and actuator is a complex process.
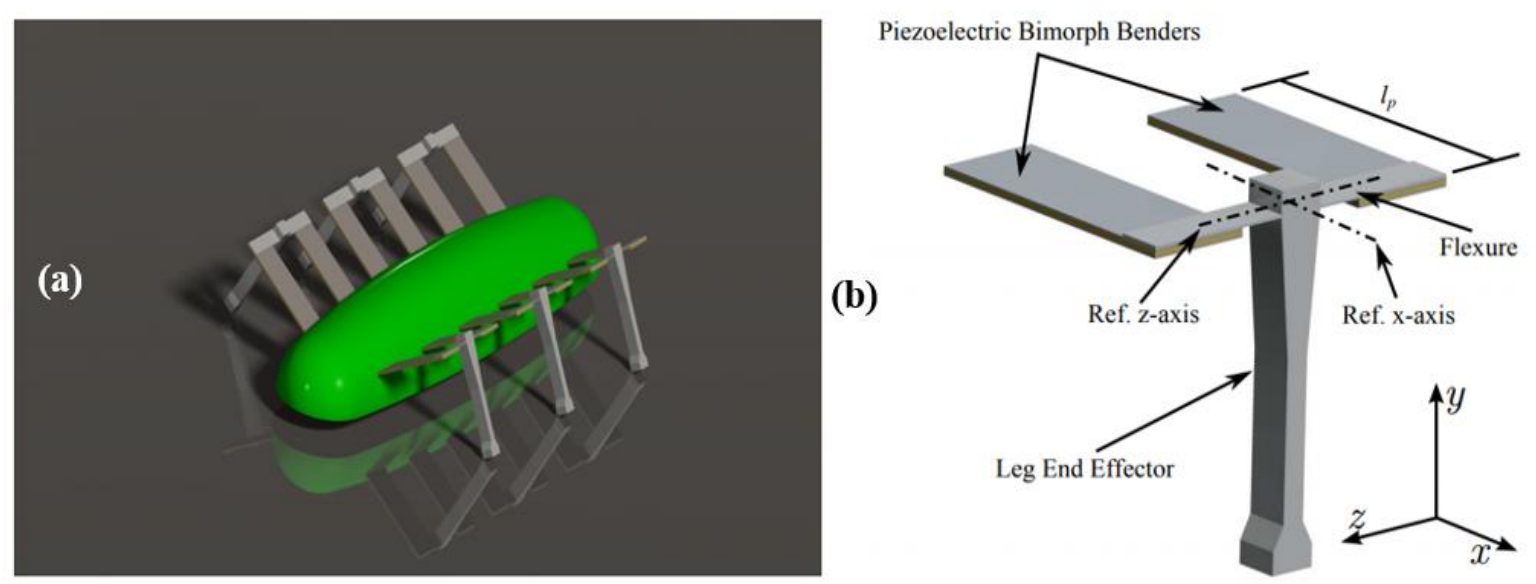

Figure 10. Schematic representation of (a) a miniature robot and $(b)$ the structure of a two-degree of freedom robotic leg (Rios, Fleming, \& Yong, 2015).

To reduce some of the aforementioned complexities the robotic engineers used piezoelectric actuators in the miniaturized robotic legs because piezoelectric actuators have lightweight, high bandwidth, high force production, and low power consumption (Addington \& Schodek, 2012; Dosch et al., 1992; Lee, 1990; Smith et al., 2012; Uchino, 2017). Moreover, they also tried to reduce the degree of freedom. SA Rios, et al. (Rios et al., 2015) used piezoelectric bimorph bender as actuator to design the legs of a miniature robot that possesses three pair legs and each leg has two degrees of freedom (Figure 10).

\subsection{Flapping Micro-Air Vehicles}

Micro-Air vehicle robots (MAV) is a prototype with a length less than $15 \mathrm{~cm}$ in all dimension, and its weight is not more than $140 \mathrm{~g}$. It can fly above $10 \mathrm{~km}$ for about $2 \mathrm{~h}$ (Shyy, Berg, \& Ljungqvist, 1999). MAV can move its wings like birds. This robot twisting its wings using the embedded bones and muscles. Instead of muscles, actuators were handled in MAV robots, which able to twist wings and hence the robot can fly (Figure 11). Piezoelectric materials are widely used to design such flapping micro-vehicles. They have high bandwidth, high output force, high power density, and they can be miniaturized (Niezrecki, Brei, Balakrishnan, \& Moskalik, 2001) .T. Ozaki, et al. designed a MAV, which the embedded actuators based on piezoelectric materials. They used the direct-driven mechanism in their prototype. Usually, for designing the MAV robots, the transmission system is used to transfer the symmetric motion to the wings of MAV (Figure 12) (Finio, Shang, \& Wood, 2009). However, in the direct-driven system, the produced motion, by a piezoelectric actuator, is directly transmitted to the wings (Ozaki \& Hamaguchi, 2018b). 


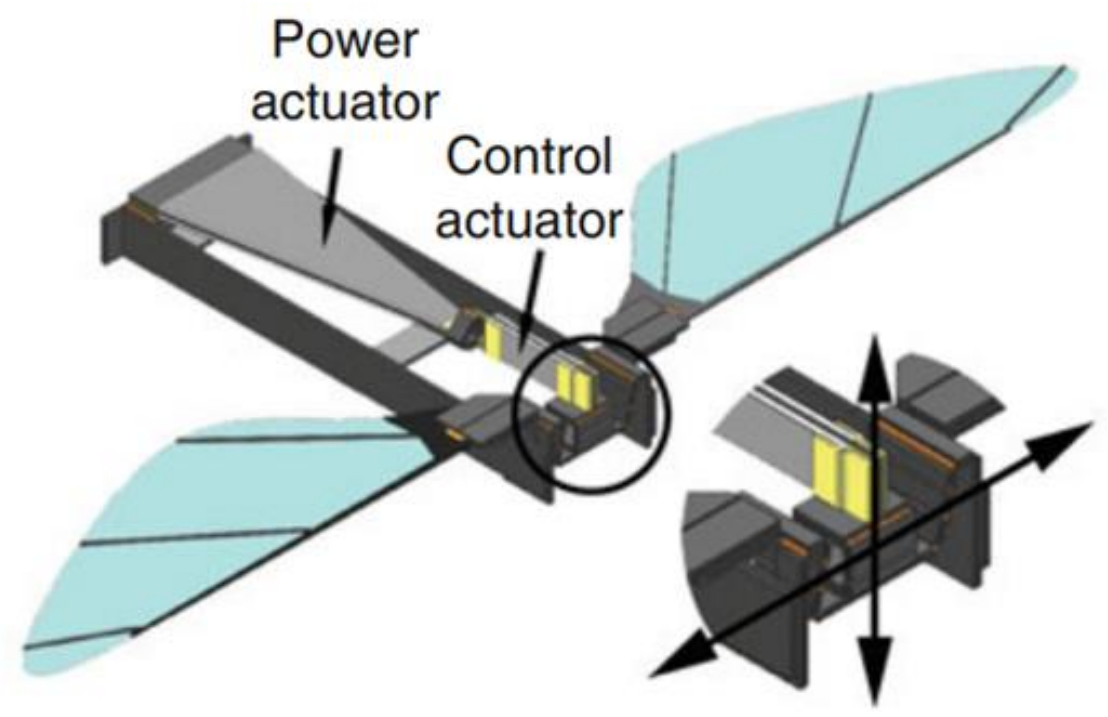

Figure 11. Schematic representation of Flapping Micro-Air Vehicles (H. Tanaka et al., 2012).

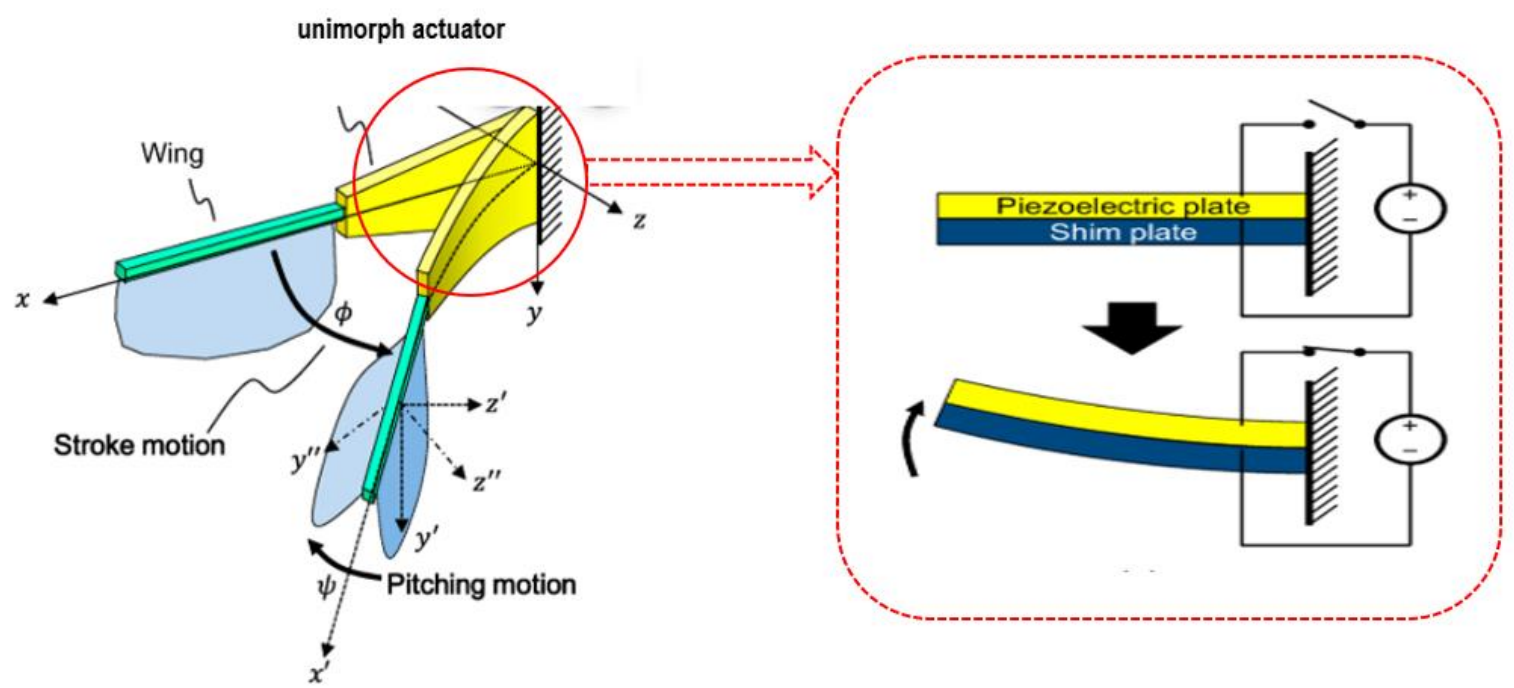

Figure 12. Design of wings in a flapping micro-air vehicle using a piezoelectric actuating system (Ozaki \& Hamaguchi, 2018a).

\subsection{Robotic Fish}

Robotic fish is designed for swimming a liquid (Kheirikhah et al., 2010), and can be used in some cooperative applications such as research about the underwater environment, archaeology, finding patrol in the seas, and it can be used for research in some complex environment in-depth oceans. It is difficult for an ordinary robot because the motion should be well programmed (Yu, Chen, Wu, \& Wang, 2016). The robotic fish can swim underwater using its wings and propellers (J. Wang, 2014). SMA-based actuators are the best choice that can give proper motion to the robot, also they have a big actuation force, long operational life, and high recovery stress (>500Mpa, which are a hundred times as greater as a biological muscle) (Z. Wang, Wang, Li, \& Hang, 2009).

There are more researches in the literature that used SMA for actuating robotic fish. Tao et al proposed a ferromagnetic shape memory alloy (FSMA) for designing a caudal peduncle actuator. This actuator was able to provide a convenient force for shaking the tail of the robotic fish (Tao, Liang, \& Taya, 2006).

Likewise, Cho et al in 2008 was designed and fabricated a small (in the scope of a centimeter) propulsion system for robotic fish. They embedded SMA actuator in all flexure joints and the electrical wiring and attachment pads, for the SMA-based actuators, in a single layer of a copper laminated polymer film. Also, they put this layer between to glass-fiber layers, and instead of using actuator for each joint, only a single actuator was used to rotate all of the joints in the robotic fish (Cho, Hawkes, Quinn, \& Wood, 2008). 


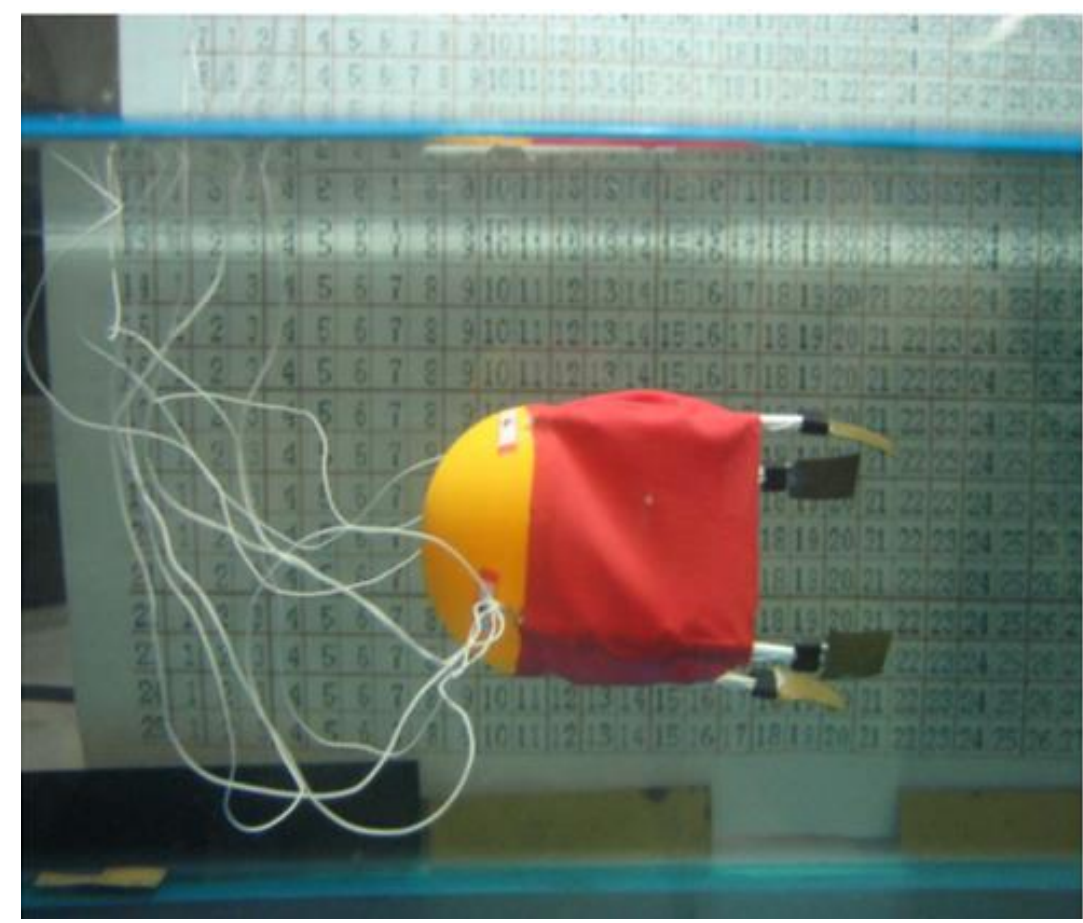

Figure 13. Jellyfish-like microrobot (Yang, Ye, \& Guo, 2007).

In 2007, Y Yang and his coworkers proposed a new type of jellyfish (Figure 13). Similar to an underwater microrobot, the robot has a length of $75 \mathrm{~mm}, 55 \mathrm{~mm}$ in diameter and its weight was only $6.5 \mathrm{~g}$. They used SMA with ionic conducting polymer film (ICPF) as an actuator to push the prototype forward during swimming. To increase ICPF movement range during swimming, it was composed of tentacles with binary mechanism, and SMA actuator to cooperate with the tentacles (which has four tentacles). Also, the frequency of input voltage in the SMA and ICPF actuators could be controlled through a frequency generator. Therefore, the input voltage the direction and speed of the microrobot jellyfish were controlled (Yang et al., 2007).

\subsection{Flower Robots}

In a parallel development of technology, the robots have a strong role in all areas of human life, especially in the industry and other technological applications. As an example, flower robots can be used as beautification, smart home service or home gardening market. The flower robot has many numerous sensible functions, such as moving operations, environmental sensing, and domestic employment compatibility. Moving is one of the more interesting functions, which includes blooming of a flower, the sagging of the stem and the stirring of the leaves by wind (Kheirikhah et al., 2010).

Carnegi Mellon University researchers were the first how proposed the robotic flower that had seven degrees of freedom (DOF), which provided motion of the stem in two different directions, and the other DOF were used to move the flower. A DC motor was used as the source of the actuator (H. Park et al., 2007). On the other hand, Huang et al. (H. L. Huang et al., 2008) were proposed a new robotic flower, that its actuators were based on SMA materials. They were designed the robotic flower (Figure 14a) in two steps, firstly in 2007 they were fabricated the stem structure by a silica gel rod (Figure 14b), which its diameter is about $8 \mathrm{~mm}$ and $50 \mathrm{~mm}$ length, and they used three coils shaped SMA wires embedded inside the rod. Thus, the motion of the stem was controlled by those actuators. In 2008, they focused on the motion functionalities of the petals and leafage of the flower robot. The motion of the petals consists of three parts (Figure 14a), including silicone rod, cap, and localizers. The actuator was connected to a spring, with one side, and the other side of SMA wire was connected with the power supply. The biased voltage could move the actuator to downward, and thus, the petals lightening and they constricted with the localizer (Figure 14c). The leafages were also having the same mechanism. 


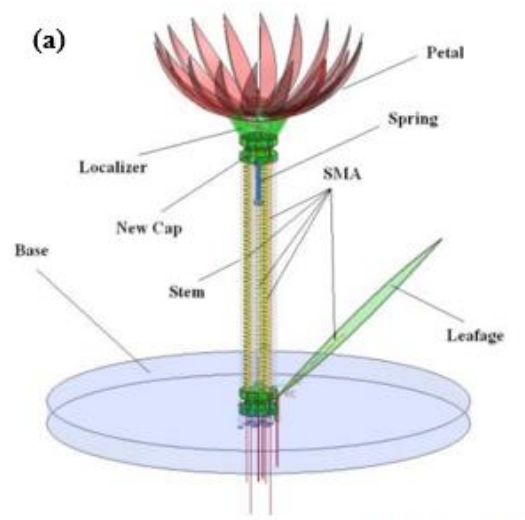

(c)

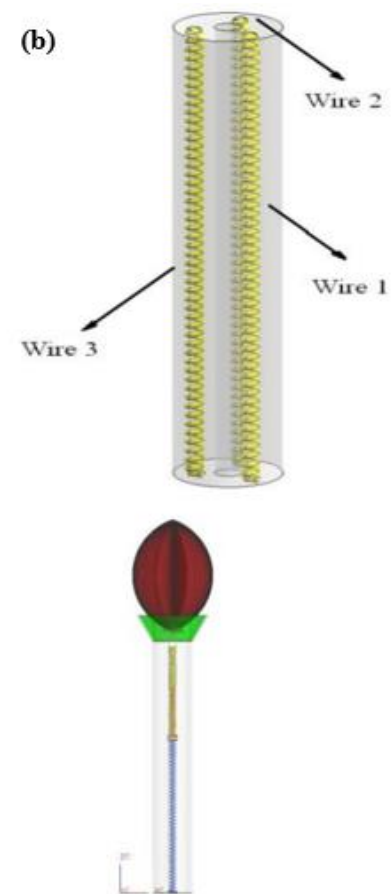

Figure 14. (a) The structure of a robotic flower, (b) stem structure, and (c) dynamic system of the petals in the robotic flower (H. L. Huang, Park, \& Park, 2008).

\section{Concluding Remarks}

Smart materials have a major and significant role in the development of the modern age because they have a special capability to solve some problems in modern technology. Therefore, they are more focused on researchers and designers. Also, smart materials SMAs and piezoelectric materials having comparably more used in technological applications, especially in the robotic system, which more widely handled for constructing actuators.

SMAs are easily recovered to their original shape after deformation, which is known as the shape memory effect. SMA-based actuators are used in a locomotion robot, manipulator and microrobot. Also, piezoelectric materials can change mechanical energy into voltage and vice versa. These abilities are known as the piezoelectric effect. Therefore piezoelectric materials can also be handled as an actuator in robotic systems.

There is more opportunity for researchers and robotic engineers, especially in the micro-robotic area. To improve robotic abilities, one can improve the actuation system in their innovations. Using SMA and piezoelectric materials as an actuator instead of DC motor is a key point because they have a fast response to applied signals and stress, and they have a smaller size and lower mass density compared to DC motors. Therefore they will be selected in the micro-robotic field and all other advance fields of technology as an actuator. Besides, there are other kinds of smart materials that should be investigated in this area.

\section{Acknowledgments:}

Thanks for University of Raparin and Firat University for financial support.

\section{References}

Addington, M., \& Schodek, D. (2012). Smart Materials and Technologies in Architecture: For the Architecture and Design Professions: Routledge.

Advincula, A. P., \& Song, A. (2007). The role of robotic surgery in gynecology. Current Opinion in Obstetrics and Gynecology, 19(4), 331-336.

Ahmadi, A., Mahdavian, M., Rad, N. F., Yousefi-Koma, A., Alidoost, F., \& Bazrafshani, M. A. (2015). Design and fabrication of a Robotic Hand using shape memory alloy actuators. Paper presented at the 2015 3rd RSI International Conference on Robotics and Mechatronics (ICROM). 
Alaneme, K. K., \& Okotete, E. A. (2016). Reconciling viability and cost-effective shape memory alloy options-A review of copper and iron based shape memory metallic systems. Engineering Science and Technology, an International Journal, 19(3), 15821592.

Arber, W. (2009). The impact of science and technology on the civilization. Biotechnology advances, 27(6), 940-944.

Astudillo, J. A., Sporn, E., Bachman, S., Miedema, B., \& Thaler, K. (2009). Transgastric cholecystectomy using a prototype endoscope with 2 deflecting working channels (with video). Gastrointestinal endoscopy, 69(2), 297-302.

Aydoğdu, Y., Kök, M., Dağdelen, F., Aydoğdu, A., Turabi, A. S., \& Karaca, H. E. (2016). The effects of thermal procedure on transformation temperature, crystal structure and microstructure of $\mathrm{Cu}$-Al-Co shape memory alloy. Paper presented at the Journal of Physics: Conference Series.

Balamurugan, V., \& Narayanan, S. (2008). A piezolaminated composite degenerated shell finite element for active control of structures with distributed piezosensors and actuators. Smart materials and Structures, 17(3), 035031.

Bennett, J., Mecrow, B., Atkinson, D., Maxwell, C., \& Benarous, M. (2011). Fault-tolerant electric drive for an aircraft nose wheel steering actuator. IET electrical systems in transportation, 1(3), 117-125.

Bogue, R. (2009). Shape-memory materials: a review of technology and applications. Assembly Automation, 29 (3), $214-219$.

Book, W. J. (1986). Low cost automation with lighter, versatile machines. IFAC Proceedings Volumes, 19(13), 23-28.

Brose, S. W., Weber, D. J., Salatin, B. A., Grindle, G. G., Wang, H., Vazquez, J. J., \& Cooper, R. A. (2010). The role of assistive robotics in the lives of persons with disability. American Journal of Physical Medicine \& Rehabilitation, 89(6), 509-521.

Buytoz, S., Dagdelen, F., Qader, I., Kok, M., \& Tanyildizi, B. (2019). Microstructure Analysis and Thermal Characteristics of NiTiHf Shape Memory Alloy with Different Composition. Metals and Materials International, 1-12.

Carneiro, R. L. (1974). A Reappraisal of the Roles of Technology and Organization in the Origin of Civilization. American Antiquity, 39(2Part1), 179-186.

Casper, J., \& Murphy, R. R. (2003). Human-robot interactions during the robot-assisted urban search and rescue response at the world trade center. IEEE Transactions on Systems, Man, and Cybernetics, Part B (Cybernetics), 33(3), 367-385.

Cattafesta III, L. N., \& Sheplak, M. (2011). Actuators for active flow control. Annual Review of Fluid Mechanics, 43, $247-272$.

Chance, B., Ben-Zvi, D., Garfield, J., \& Medina, E. (2007). The Role of Technology in Improving Student Learning of Statistics.

Chaudhry, Z., \& Rogers, C. A. (1991). Bending and shape control of beams using SMA actuators. Journal of intelligent material systems and structures, 2(4), 581-602.

Cho, K.-J., Hawkes, E., Quinn, C., \& Wood, R. J. (2008). Design, fabrication and analysis of a body-caudal fin propulsion system for a microrobotic fish. Paper presented at the 2008 IEEE international Conference on Robotics and Automation.

Chua, P. Y., Ilschner, T., \& Caldwell, D. G. (2003). Robotic manipulation of food products-a review. Industrial Robot: An International Journal, 30(4), 345-354.

Chuanzhong, Z. (1993). Development of Piezoelectric Materials and Their Applications [J]. Piezoelectrics \& Acoustooptics, 3.

Colorado, J., Barrientos, A., Rossi, C., \& Breuer, K. S. (2012). Biomechanics of smart wings in a bat robot: morphing wings using SMA actuators. Bioinspiration \& biomimetics, 7(3), 036006.

Culjat, M., King, C.-H., Franco, M., Bisley, J., Grundfest, W., \& Dutson, E. (2008). Pneumatic balloon actuators for tactile feedback in robotic surgery. Industrial Robot: An International Journal, 35(5), 449-455.

Culp, G. W. (1992). Piezoelectric robotic articulation: Google Patents.

Cura, V. O. D., Cunha, F. L., Aguiar, M. L., \& Cliquet Jr, A. (2003). Study of the different types of actuators and mechanisms for upper limb prostheses. Artificial organs, 27(6), 507-516.

Dadfarnia, M., Jalili, N., Xian, B., \& Dawson, D. M. (2003). Lyapunov-based piezoelectric control of flexible cartesian robot manipulators. Paper presented at the Proceedings of the 2003 American Control Conference, 2003.

Daerden, F., \& Lefeber, D. (2002). Pneumatic artificial muscles: actuators for robotics and automation. European journal of mechanical and environmental engineering, 47(1), 11-21.

Daerden, F., Lefeber, D., Verrelst, B., \& Van Ham, R. (2001). Pleated pneumatic artificial muscles: actuators for automation and robotics. Paper presented at the 2001 IEEE/ASME International Conference on Advanced Intelligent Mechatronics. Proceedings (Cat. No. 01Th8556).

Dagdelen, F., Aldalawi, M., Kok, M., \& Qader, I. (2019). Influence of Ni addition and heat treatment on phase transformation temperatures and microstructures of a ternary $\mathrm{CuAlCr}$ alloy. The European Physical Journal Plus, 134(2), 66.

Dagdelen, F., Kok, M., \& Qader, I. (2019). Effects of Ta Content on Thermodynamic Properties and Transformation Temperatures of Shape Memory NiTi Alloy. Metals and Materials International, 1-8. doi: https://doi.org/10.1007/s12540-019-00298-z

Dağdelen, F., Malkoç, T., Kök, M., \& Ercan, E. (2016). Comparison of the transformation temperature, microstructure and magnetic properties of Co-Ni-Al and Co-Ni-Al-Cr shape memory alloys. The European Physical Journal Plus, 131(6), 196.

De Rossi, D., Suzuki, M., Osada, Y., \& Morasso, P. (1992). Pseudomuscular gel actuators for advanced robotics. Journal of intelligent material systems and structures, 3(1), 75-95.

Denoyer, K., \& Kwak, M. (1996). Dynamic modelling and vibration suppression of a swelling structure utilizing piezoelectric sensors and actuators. Journal of Sound and Vibration, 189(1), 13-31.

Dökmeci, M. (1983). Dynamic applications of piezoelectric crystals. Part 3: Experimental studies. Shock Vibration Digest, 15.

Dolghi, O., Strabala, K. W., Wortman, T. D., Goede, M. R., Farritor, S. M., \& Oleynikov, D. (2011). Miniature in vivo robot for laparoendoscopic single-site surgery. Surgical endoscopy, 25(10), 3453-3458.

Dosch, J. J., Inman, D. J., \& Garcia, E. (1992). A self-sensing piezoelectric actuator for collocated control. Journal of Intelligent Material Systems and Structures, 3(1), 166-185.

Drucker, P. (2012). Technology, management and society: Routledge. 
Duchaud, J. L., Hlioui, S., Louf, F., Ojeda, J., \& Gabsi, M. (2014). Modeling and optimization of a linear actuator for a two-stage valve tappet in an automotive engine. IEEE Transactions on Vehicular Technology, 64(10), 4441-4448.

Ercan, E., Dagdelen, F., \& Qader, I. (2019). Effect of tantalum contents on transformation temperatures, thermal behaviors and microstructure of CuAlTa HTSMAs. Journal of Thermal Analysis and Calorimetry, 1-8. doi: https://doi.org/10.1007/s10973-01908418-y

Finio, B. M., Shang, J. K., \& Wood, R. J. (2009). Body torque modulation for a microrobotic fly. Paper presented at the 2009 IEEE International Conference on Robotics and Automation.

Goldenberg, E., Shabtay, G., Mendlovic, E., \& Kali, E. (2014). Electromagnetic actuators for digital cameras: Google Patents.

Gray, J., \& Zhu, C. (2007). In-pipe robot for inspection and sampling tasks. Industrial Robot: An International Journal.

Hines, L., Petersen, K., Lum, G. Z., \& Sitti, M. (2017). Soft actuators for small-scale robotics. Advanced materials, $29(13), 1603483$.

Howard, D. A., \& Walker, K. C. (1993). Landing gear drag strut actuator having self-contained pressure charge for emergency use: Google Patents.

Huang, H. L., Park, S.-H., \& Park, J.-O. (2008). Shape memory alloy based flower robot. Paper presented at the 39th International Symposium on Robotics, Seoul, Korea (October 2008).

Huang, W. (2002). On the selection of shape memory alloys for actuators. Materials \& design, 23(1), 11-19.

Huang, W., \& Toh, W. (2000). Training two-way shape memory alloy by reheat treatment. Journal of materials science letters, 19(17), 1549-1550.

Huber, J., Fleck, N., \& Ashby, M. (1997). The selection of mechanical actuators based on performance indices. Proceedings of the Royal Society of London. Series A: Mathematical, physical and engineering sciences, 453(1965), 2185-2205.

Hunter, I. W., Hollerbach, J. M., \& Ballantyne, J. (1991). A comparative analysis of actuator technologies for robotics. Robotics Review, 2, 299-342.

Hunter, I. W., \& Lafontaine, S. (1992). A comparison of muscle with artificial actuators. Paper presented at the Technical Digest IEEE Solid-State Sensor and Actuator Workshop.

Ikuta, K., Tsukamoto, M., \& Hirose, S. (1988). Shape memory alloy servo actuator system with electric resistance feedback and application for active endoscope. Paper presented at the Proceedings. 1988 IEEE International Conference on Robotics and Automation.

Inoue, A., \& Deng, M. (2007). Piezoelectric actuator based adaptive vibration control of flexible arm. IFAC Proceedings Volumes, 40(13), 197-202.

Jacobsen, G., Berger, R., \& Horgan, S. (2003). The role of robotic surgery in morbid obesity. Journal of laparoendoscopic \& advanced surgical techniques, 13(4), 279-283.

Jaffe, B. (2012). Piezoelectric ceramics (Vol. 3): Elsevier.

Jani, J. M., Leary, M., Subic, A., \& Gibson, M. A. (2014). A review of shape memory alloy research, applications and opportunities. Materials \& Design (1980-2015), 56, 1078-1113.

Janocha, H. (2004). Actuators: Springer.

Jbaily, A., \& Yeung, R. W. (2015). Piezoelectric devices for ocean energy: a brief survey. Journal of Ocean Engineering and Marine Energy, 1(1), 101-118.

Karabegović, I. (2016). The role of industrial robots in the development of automotive industry in China. International Journal of Engineering Works, 3(12), 92-97.

Kawamura, K., Bagchi, S., Iskarous, M., \& Bishay, M. (1995). Intelligent robotic systems in service of the disabled. IEEE Transactions on rehabilitation engineering, 3(1), 14-21.

Kheirikhah, M. M., Rabiee, S., \& Edalat, M. E. (2010). A review of shape memory alloy actuators in robotics. Paper presented at the Robot Soccer World Cup.

Kim, B., Lee, M. G., Lee, Y. P., Kim, Y., \& Lee, G. (2006). An earthworm-like micro robot using shape memory alloy actuator. Sensors and Actuators A: Physical, 125(2), 429-437.

Kim, S. G., Franklin, D. K., \& Conner, M. P. (1995). Emergency power system for door: Google Patents.

Kok, M., Al-Jaf, A. O. A., Çirak, Z. D., Qader, I. N., \& Özen, E. (2019). Effects of heat treatment temperatures on phase transformation, thermodynamical parameters, crystal microstructure, and electrical resistivity of NiTiV shape memory alloy. Journal of Thermal Analysis and Calorimetry. doi: https://doi.org/10.1007/s10973-019-08788-3

Kök, M., \& Ateş, G. (2017). The effect of addition of various elements on properties of NiTi-based shape memory alloys for biomedical application. The European Physical Journal Plus, 132(4), 185.

Kök, M., Qader, I. N., Mohammed, S. S., ÖNER, E., Dağdelen, F., \& Aydogdu, Y. (2020). Thermal Stability and Some Thermodynamics Analysis of Heat Treated Quaternary CuAlNiTa Shape Memory Alloy. Materials Research Express, 7.

Kök, M., Zardawi, H. S. A., Qader, I. N., \& Kanca, M. S. (2019). The effects of cobalt elements addition on Ti2Ni phases, thermodynamics parameters, crystal structure and transformation temperature of NiTi shape memory alloys. The European Physical Journal Plus, 134(5), 197. doi: https://doi.org/10.1140/epjp/i2019-12570-9

Kolesar, E. S. (1998). Piezoelectric tactile sensor: Google Patents.

Kumbhar, S., \& Gawade, S. A SURVEY OF DIFFERENT ACTUATOR TECHNOLOGIES.

Laumond, J.-P. (1998). Robot motion planning and control (Vol. 229): Springer.

Lee, C. (1990). Theory of laminated piezoelectric plates for the design of distributed sensors/actuators. Part I: Governing equations and reciprocal relationships. The Journal of the Acoustical Society of America, 87(3), 1144-1158.

Liang, C., \& Rogers, C. (1992). Design of shape memory alloy actuators. Journal of Mechanical Design, 114(2), $223-230$.

Liu, L., Towfighian, S., \& Hila, A. (2015). A review of locomotion systems for capsule endoscopy. IEEE reviews in biomedical engineering, 8, 138-151. 
Ma, N., Song, G., \& Lee, H. (2004). Position control of shape memory alloy actuators with internal electrical resistance feedback using neural networks. Smart materials and Structures, 13(4), 777.

Maeno, T., \& Hino, T. (2006). Miniature five-fingered robot hand driven by shape memory alloy actuators. Paper presented at the Proceedings of the 12th IASTED International Conference, Robotics and Applications.

Mavroidis, C. (2002). Development of advanced actuators using shape memory alloys and electrorheological fluids. Journal of Research in Nondestructive Evaluation, 14(1), 1-32.

Mazzolai, B., Margheri, L., Cianchetti, M., Dario, P., \& Laschi, C. (2012). Soft-robotic arm inspired by the octopus: II. From artificial requirements to innovative technological solutions. Bioinspiration \& biomimetics, 7(2), 025005.

Mubin, O., Stevens, C. J., Shahid, S., Al Mahmud, A., \& Dong, J.-J. (2013). A review of the applicability of robots in education. Journal of Technology in Education and Learning, 1(209-0015), 13.

Nakao, S., Tokunaga, T., Yamane, Y., \& Saka, N. (1999). Linear actuator and optical equipment using the same: Google Patents.

Niezrecki, C., Brei, D., Balakrishnan, S., \& Moskalik, A. (2001). Piezoelectric actuation: state of the art.

Ochoński, W. (2010). Application of shape memory materials in fluid sealing technology. Industrial Lubrication and Tribology, 62(2), 99-110.

Oldham, K., Rhee, C.-H., Ryou, J.-H., Polcawich, R., \& Pulskamp, J. (2009). Lateral thin-film piezoelectric actuators for bio-inspired micro-robotic locomotion. Paper presented at the ASME 2009 International Design Engineering Technical Conferences and Computers and Information in Engineering Conference.

Otsuka, K., \& Shimizu, K. (1986). Pseudoelasticity and shape memory effects in alloys. International Metals Reviews, 31(1), 93-114.

Ozaki, T., \& Hamaguchi, K. (2018a). Electro-Aero-Mechanical Model of Piezoelectric Direct-Driven Flapping-Wing Actuator. Applied Sciences, 8(9), 1699.

Ozaki, T., \& Hamaguchi, K. (2018b). Performance of direct-driven flapping-wing actuator with piezoelectric single-crystal PINPMN-PT. Journal of Micromechanics and Microengineering, 28(2), 025007.

Park, H., Jung, S., Choi, J., Park, S., Yoon, C., \& Park, J. (2007). A study on the moving mechanism for flower robot. Paper presented at the 2007 International Conference on Control, Automation and Systems.

Park, J.-S., \& Kim, J.-H. (2005). Analytical development of single crystal macro fiber composite actuators for active twist rotor blades. Smart materials and Structures, 14(4), 745.

Park, Y. S., Kang, H., Ewing, T. F., Faulring, E. L., DeJong, B. P., Peshkin, M. A., \& Colgate, J. E. (2005). Semi-autonomous Telerobotic Manipulation: A Viable Approach for Space Structure Deployment and Maintenance. Paper presented at the AIP Conference Proceedings.

Pelrine, R. E., \& Kornbluh, R. D. (2003). Electroactive polymer devices: Google Patents.

Pons, J. L. (2005). Emerging actuator technologies: a micromechatronic approach: John Wiley \& Sons.

Poussot-Vassal, C., Sename, O., Dugard, L., Gaspar, P., Szabo, Z., \& Bokor, J. (2008). A new semi-active suspension control strategy through LPV technique. Control Engineering Practice, 16(12), 1519-1534.

Prensky, M. (2008). The role of technology. Educational Technology, 48(6).

Price, A., Jnifene, A., \& Naguib, H. (2007). Design and control of a shape memory alloy based dexterous robot hand. Smart Materials and Structures, 16(4), 1401.

Qader, I. N., Kök, M., \& Dağdelen, F. (2019). Effect of heat treatment on thermodynamics parameters, crystal and microstructure of (Cu-Al-Ni-Hf) shape memory alloy. Physica B: Condensed Matter, 553, 1-5. doi: https://doi.org/10.1016/j.physb.2018.10.021

Qader, I. N., Kök, M., Dağdelen, F., \& Aydogdu, Y. (2019). A Review of Smart Materials: Researches and Applications. El-Cezerî Journal of Science and Engineering, 6(3), 755-788. doi: https://doi.org/10.31202/ecjse.562177

Quinones-Hinojosa, A. (2012). Schmidek and Sweet: Operative Neurosurgical Techniques 2-Volume Set: Indications, Methods and Results (Expert Consult-Online and Print) (Vol. 2): Elsevier Health Sciences.

Ramos, A. C., Zundel, N., Neto, M. G., \& Maalouf, M. (2008). Human hybrid NOTES transvaginal sleeve gastrectomy: initial experience. Surgery for Obesity and Related Diseases, 4(5), 660-663.

Rao, A., Srinivasa, A. R., \& Reddy, J. N. (2015). Design of shape memory alloy (SMA) actuators (Vol. 3): Springer.

Rios, S. A., Fleming, A. J., \& Yong, Y. K. (2015). Design of a two degree of freedom resonant miniature robotic leg. Paper presented at the 2015 IEEE International Conference on Advanced Intelligent Mechatronics (AIM).

Robins, B., Dautenhahn, K., Te Boekhorst, R., \& Billard, A. (2005). Robotic assistants in therapy and education of children with autism: can a small humanoid robot help encourage social interaction skills? Universal Access in the Information Society, 4(2), $105-120$.

Roth, Z. S. (2002). The role of robotics in freshmen engineering curricula. Paper presented at the Proceedings of the 5th Biannual World Automation Congress.

Schoeny, S., \& Nelson, G. (2007). Modular industrial equipment facility: Google Patents.

Seelecke, S., \& Muller, I. (2004). Shape memory alloy actuators in smart structures: Modeling and simulation. Applied Mechanics Reviews, 57(1), 23-46.

Shi, Z., Pan, J., Tian, J., Huang, H., Jiang, Y., \& Zeng, S. (2019). An Inchworm-inspired Crawling Robot. Journal of Bionic Engineering, 16(4), 582-592.

Shimao, D., Inoue, K., \& Kurata, T. (2013). Precision press device and press load control method thereof: Google Patents.

Shyy, W., Berg, M., \& Ljungqvist, D. (1999). Flapping and flexible wings for biological and micro air vehicles. Progress in aerospace sciences, 35(5), 455-505.

Smith, G. L., Pulskamp, J. S., Sanchez, L. M., Potrepka, D. M., Proie, R. M., Ivanov, T. G., . . Meyer, C. D. (2012). PZT-based piezoelectric MEMS technology. Journal of the American Ceramic Society, 95(6), 1777-1792. 
Sofla, A., Elzey, D., \& Wadley, H. (2008). Two-way antagonistic shape actuation based on the one-way shape memory effect. Journal of Intelligent Material Systems and Structures, 19(9), 1017-1027.

Sohn, J., Kim, G.-W., \& Choi, S.-B. (2018). A state-of-the-art review on robots and medical devices using smart fluids and shape memory alloys. Applied Sciences, 8(10), 1928.

Solmaz, S., Akar, M., \& Shorten, R. (2008). Adaptive rollover prevention for automotive vehicles with differential braking. IFAC Proceedings Volumes, 41(2), 4695-4700.

Starr, M. B., \& Wang, X. (2015). Coupling of piezoelectric effect with electrochemical processes. Nano Energy, 14, $296-311$.

Sulchek, T., Minne, S., Adams, J., Fletcher, D., Atalar, A., Quate, C., \& Adderton, D. (1999). Dual integrated actuators for extended range high speed atomic force microscopy. Applied Physics Letters, 75(11), 1637-1639.

Swanson, D. A. (1993). Active engine mounts for vehicles: SAE Technical Paper.

Tan, X. (2002). Control of smart actuators.

Tanaka, H., Finio, B. M., Karpelson, M., Pérez-Arancibia, N. O., Sreetharan, P. S., Whitney, J. P., \& Wood, R. J. (2012). Insect Flight and Micro Air Vehicles (MAVs). Encyclopedia of Nanotechnology, 1096-1109.

Tanaka, Y., \& Yamada, A. (1991). A rotary actuator using shape memory alloy for a robot-analysis of the response with load. Paper presented at the Proceedings IROS'91: IEEE/RSJ International Workshop on Intelligent Robots and Systems' 91.

Tao, T., Liang, Y.-C., \& Taya, M. (2006). Bio-inspired actuating system for swimming using shape memory alloy composites. International Journal of Automation and Computing, 3(4), 366-373.

Tichý, J., Erhart, J., Kittinger, E., \& Privratska, J. (2010). Fundamentals of piezoelectric sensorics: mechanical, dielectric, and thermodynamical properties of piezoelectric materials: Springer Science \& Business Media.

Toru, S. (2008). Fast and accurate position control of shape memory alloy actuators. Master Degree Internship Report, Universityof Paris-Sud.

Tzou, H., Lee, H.-J., \& Arnold, S. (2004). Smart materials, precision sensors/actuators, smart structures, and structronic systems. Mechanics of Advanced Materials and Structures, 11(4-5), 367-393.

Tzou, H., \& Natori, M. (2001). Piezoelectric Materials and Continua, Encyclopedia of Vibration: Academic Press, London, UK.

Uchino, K. (2017). Advanced piezoelectric materials: Science and technology: Woodhead Publishing.

Uttley, A. E., Chambers, P. W., Blackwell, N., \& Weller, B. (2002). Actuator system for aerospace controls and functions: Google Patents.

Villoslada, A., Flores-Caballero, A., Copaci, D., Blanco, D., \& Moreno, L. (2014). High-displacement fast-cooling flexible Shape Memory Alloy actuator: Application to an anthropomorphic robotic hand. Paper presented at the 2014 IEEE-RAS International Conference on Humanoid Robots.

Wang, B., \& Zhu, S. (2018). Seismic behavior of self-centering reinforced concrete wall enabled by superelastic shape memory alloy bars. Bulletin of Earthquake Engineering, 16(1), 479-502.

Wang, J. (2014). Robotic fish: Development, modeling, and application to mobile sensing: Michigan State University. Electrical Engineering.

Wang, Z., Wang, Y., Li, J., \& Hang, G. (2009). A micro biomimetic manta ray robot fish actuated by SMA. Paper presented at the 2009 IEEE International Conference on Robotics and Biomimetics (ROBIO).

Webb, G. V., Lagoudas, D. C., \& Kurdila, A. J. (1998). Hysteresis modeling of SMA actuators for control applications. Journal of intelligent material systems and structures, 9(6), 432-448.

Wood, R., Steltz, E., \& Fearing, R. (2005). Optimal energy density piezoelectric bending actuators. Sensors and Actuators A: Physical, 119(2), 476-488.

Yang, Y., Ye, X., \& Guo, S. (2007). A new type of jellyfish-like microrobot. Paper presented at the 2007 IEEE International Conference on Integration Technology.

Yasui, T., \& Naito, M. (1981). Electric control circuit for safety apparatus in automotive vehicles: Google Patents.

Yoichi, M. (2006). Applications of piezoelectric actuator. NEC Technical Journal, 1(5), 82-86.

Yongning, T., \& Fengbai, T. (1988). Variable speed AC motor: Google Patents.

Yu, J., Chen, S., Wu, Z., \& Wang, W. (2016). On a miniature free-swimming robotic fish with multiple sensors. International Journal of Advanced Robotic Systems, 13(2), 62. 